\title{
Dondurma Üretiminde Bazı Baharat Uçucu Yağlarının Kullanım Olanakları
}

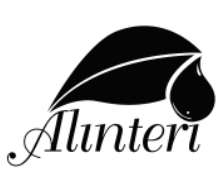

\begin{tabular}{|c|c|}
\hline Araştırma / Research & Emine $M A C \dot{I} T^{1^{*}}$, Abdullah $C ̧ A \breve{G} L A R^{2}$, Ihsan BAKIRCI ${ }^{3}$ \\
\hline $\begin{array}{l}\text { Geliş Tarihi / Received } \\
\text { 20.08.2017 }\end{array}$ & ${ }^{\text {I} B a y b u r t ~ U ̈ n i v e r s i t e s i ~ M u ̈ h e n d i s l i k ~ F a k u ̈ l t e s i ~ G i d a ~ M u ̈ h e n d i s l i g ̆ i ~ B o ̈ l u ̈ m u ̈, ~}$ \\
\hline $\begin{array}{l}\text { Kabul Tarih / Accepted } \\
06.11 .2017\end{array}$ & $\begin{array}{c}{ }^{2} \text { Afyon Kocatepe Üniversitesi Mühendislik Fakültesi Gida Mühendisliği } \\
\text { Bölümü, Afyonkarahisar-Tüekiye }\end{array}$ \\
\hline $\begin{array}{l}\text { DOI } \\
\text { 10.28955/alinterizbd.335399 }\end{array}$ & $\begin{array}{c}{ }^{3} \text { Atatürk Üniversitesi Ziraat Fakültesi Gida Mühendisliği Bölümü, } \\
\text { Erzurum- Türkiye }\end{array}$ \\
\hline $\begin{array}{l}\text { ISSN } 2564-7814 \\
e-I S S N 2587-2249\end{array}$ & *e-posta: emacit@bayburt.edu.tr \\
\hline
\end{tabular}

Öz: Bu araştırmada, 4 farklı baharat uçucu yağı (Hindistan cevizi, limon kabuğu, karanfil ve tarçın) 2 farklı oranda $(\% 0,2$ ve $\% 0,4)$ kullanılarak üretilen dondurma örneklerinin depolama süresince bazı fiziksel, kimyasal, duyusal ve mikrobiyolojik özellikleri incelenmiştir.

Elde edilen bulgulara göre, baharat uçucu yağı ilavesinin dondurma örneklerinin fiziksel ve kimyasal özellikleri üzerinde önemli derecede etkili olmadığ $(\mathrm{P}>0,05)$ ancak erime oranlarının depolama süresince arttığı tespit edilmiştir. \%0,2 düzeyinde Hindistan cevizi uçucu yağı içeren örnek duyusal değerlendirmelerde en fazla, \%0,4 düzeyinde karanfil uçucu yağı içeren örnek ise en az beğenilen örnek olmuştur. Genel olarak \%0,2 düzeyinde baharat uçucu yağı içeren örnekler \%0,4 düzeyinde içeren örneklere göre daha fazla beğenilmiştir. Dondurma örneklerinin mikrobiyolojik özellikler bakımından TS 4265 Dondurma Standardı'na uygun olduğu tespit edilmiştir. Bu çalışma ile bazı baharat uçucu yağlarının dondurma üretiminde doğal aroma maddesi olarak kullanılabileceği belirlenmiştir.

Anahtar Kelimeler: Dondurma, uçucu yağ, Hindistan cevizi, limon kabuğu, karanfil, tarçın

\section{The Possibilities of Using Some Spice Essential Oils in Ice Cream Production}

\begin{abstract}
In present study, some physical, chemical, sensory and microbiological characteristics of ice cream samples produced by using 4 different essential oils (Coconut, lemon bark, clove and cinnamon) in 2 different levels ( $0.2 \%$ and $0.4 \%)$ were investigated.

The findings indicated that although the addition of essential oil was not significantly effective on the physical and chemical properties of ice cream samples $(\mathrm{P}>0.05)$, the melting rates increased during storage. The sample with $0.2 \%$ coconut essential oil was the most favorite sample in sensory evaluations, while the sample with $0.4 \%$ clove essential oil was the least favorite sample. In general, samples with $0.2 \%$ essential oil were more appreciated than samples with $0.4 \%$. It has been determined that ice cream samples conformed to TS 4265 Ice Cream Standard (Turkish Standard) in terms of microbiological properties. With this study, it was determined that some essential oils can be used as a natural aroma substance in the production of ice cream.
\end{abstract}

Keywords: Ice cream, essential oil, coconut, lemon bark, clove, cinnamon

\section{GİRiş}

Dondurma; süt, şeker, stabilizör, emülsifier ve aroma maddeleri gibi bileşenleri içeren dondurulmuş bir karışımdır (Cruz ve ark., 2009). Aroma maddeleri dondurma tüketimi ve tüketici kabul edilebilirliği açısından en önemli bileşenlerdendir. Dondurma üretiminde doğal aroma maddeleri kullanıldığı gibi sentetik aroma maddeleri de kullanılmaktadır. Sentetik olanlar daha bol ve ucuz olduğu için daha fazla kullanılmaktadır (Akın, 2009). Ancak beslenme ve sağlık ilişkisi, tüketicilerde artan sağlıklı beslenme bilinci, gıda maddeleri üretiminde yeni arayışları beraberinde getirmiş, doğal katkı maddelerine olan talep artmıştır (Negi, 2012).

Uçucu yağlar damıtma veya presleme yoluyla, bitkilerin yaprak, meyve, kabuk ve kök kısımlarından elde edilen kompleks karışımlardır (Manikandan ve ark., 2015). Çoğu, Birleşik Devletler Gıda ve İlaç İdaresi (Food and Drug Administration, FDA) tarafindan "GRAS" kategorisinde tutulmakta ve gida katk1 maddeleri olarak onaylanmaktadır (Calo ve ark., 2015; Prakash ve ark., 2015). Kullanım amaçları başta lezzet ve koku pazarına yöneliktir (Burt, 2004). Ayrıca bazı uçucu yağların 
antimikrobiyal, antiviral, antimikotik, antitoksijenik, vb. özellikleri de olduğu çeşitli araştırmacılar ${ }^{\bullet}$ tarafından ifade edilmiştir (Feng and Zheng, 2007; Viuda-Martos ve ark., 2008).

$\mathrm{Bu}$ çalışmada, dondurma üretiminde doğal aroma maddesi olarak kullanılabilecek bazı baharat (Hindistan cevizi, limon kabuğu, karanfil, tarçın) uçucu yağlarının ve uygun konsantrasyonlarının belirlenmesi amaçlanmıştır.

\section{MATERYAL VE YÖNTEM}

Dondurma üretiminde kullanılan inek sütü ve krema Atatürk Üniversitesi Ziraat Fakültesi İşletmesi Müdürlüğü'nden; yağsız süttozu, şeker, salep ve baharat uçucu yağları Erzurum piyasasından satın alınmıştır. Dondurmaya işlenecek süt, krema ve süttozuna ait bazı özellikler Çizelge 1'de verilmiştir. Dondurma üretiminde kullanılan baharat uçucu yağları, pH metre kullanılarak \%50'lik $\mathrm{Na}_{2} \mathrm{CO}_{3}$ çözeltisi ile nötürlenmiştir.

Çizelge 1. Dondurma üretiminde kullanılan süt, krema ve süttozuna ait bazı özellikler

\begin{tabular}{lccccccc}
\hline & Asitlik (\%) & $\mathbf{p H}$ & $\begin{array}{c}\text { Kurumadde } \\
(\boldsymbol{\%})\end{array}$ & Yăg (\%) & $\begin{array}{c}\text { Özgül } \\
\text { ăğırlık }\end{array}$ & $\begin{array}{c}\text { Kül } \\
(\%)\end{array}$ & $\begin{array}{c}\text { Protein } \\
(\%)\end{array}$ \\
\hline Süt & 0,21 & 6,70 & 12,20 & 4,2 & 1,029 & 0,63 & 2,71 \\
\hline Krema & 0,40 & 6,38 & 70,65 & 66 & - & - & - \\
\hline Süttozu & 0,14 & 6,59 & 98 & 1 & - & - & - \\
\hline
\end{tabular}

\section{Dondurma Üretimi}

\%14 şeker (sakkaroz) ve \%0,4 stabilizatör madde içerecek şekilde hazırlanan miks, sıcak su banyosunda $85{ }^{\circ} \mathrm{C}$ 'de 10 dak süre ile pastörize edildikten sonra $4 \pm 1{ }^{\circ} \mathrm{C}$ 'ye soğutulmuş ve soğuk hava deposunda aynı sıcaklıkta 24 saat olgunlaşmaya bırakılmıştır. Olgunlaşmayı takiben miks, grup sayısı (9) kadar eşit parçaya bölünüp Çizelge 2'de verilen çeşit ve oranda baharat uçucu yağı eklendikten sonra dondurmaya işlenmişlerdir. Üretilen dondurmalar fiziksel, kimyasal, mikrobiyolojik ve duyusal analizler için yeterli sayıda ve steril plastik kaplara bölünerek derin dondurucuda muhafaza edilmişlerdir.

Çizelge 2. Dondurma örneklerine ilave edilen baharat uçucu yağı çeşit ve oranları

\begin{tabular}{ccc}
\hline Örnek Kodu & Baharat Uçucu Yağı & Dondurmaya katılan oran (\%) \\
\hline A1 & Limon kabuğu & 0,2 \\
\hline A2 & Limon kabuğu & 0,4 \\
\hline B1 & Hindistan Cevizi & 0,2 \\
\hline B2 & Hindistan Cevizi & 0,4 \\
\hline C1 & Tarçın & 0,2 \\
\hline C2 & Tarçın & 0,4 \\
\hline D1 & Karanfil & 0,2 \\
\hline D2 & Karanfil & 0,4 \\
\hline E (Kontrol) & - & 0,0 \\
\hline
\end{tabular}

\section{Dondurma Örneklerinde Yapılan Fiziksel ve Kimyasal Analizler}

Erime oranı Olson ve ark., (2003), hacim artışı Tekinşen (2000), asitlik, kurumadde, yağ ve protein miktarları Kurt ve ark. (2014) tarafından verilen yöntemlere göre yapılmıştır. pH tayini için uygun miktarda dondurma alınarak oda sıcaklığında $\left(20-25^{\circ} \mathrm{C}\right)$ eritildikten hemen sonra birleşik elektrotlu dijital pH-metre (WTW 340-1 marka) ile ölçüm yapılmıştır.

\section{Dondurma Örneklerinde Yapılan Duyusal Analizler}

$\mathrm{Bu}$ amaçla, dondurma örneklerinin renk ve görünüş, yapı ve kıvam, tat ve koku nitelikleri depolamanın 1., 15. ve 30. günlerinde Gıda Mühendisliği Bölümü Öğretim Elemanlarından oluşan 12 
kişilik panelist grup tarafından değerlendirilmiştir (Anonim, 1992). Değerlendirmeler 5 puan Allınteri üzerinden yapılmıştır (5 puan, çok iyi; 4, iyi; 3, az kusurlu; 2, kusurlu)

\section{Dondurma Örneklerinde Yapılan Mikrobiyolojik Analizler}

Koliform grubu bakterilerin sayımı için Violet Red Bile Agar'da (Merck) $32 \pm 1{ }^{\circ} \mathrm{C}^{\prime}$ de $24 \pm 2$ saat, psikrotrofik bakterilerin sayımı için Plate Count Agar'da (Merck) $7{ }^{\circ} \mathrm{C}$ 'de 10 gün süreyle inkübasyon gerçekleştirilmiştir. Maya ve küf sayımı için potato-dextrose agar (Meck) kullanılmışıı. Besiyerinin pH's1 \% $10^{\prime}$ luk steril tartarik asit ile 3,5'e ayarlanmış, petriler $20-25^{\circ} \mathrm{C}$ 'de 5 gün inkübe edilmiştir.

\section{İstatistiksel Analizler}

Araştırma, 4 farklı baharat uçucu yağı, 2 farklı baharat uçucu yağı düzeyi, 3 farklı depolama periyodu ve 2 tekerrür olmak üzere; $(4 \times 2 \times 3)$ faktöriyel düzenlemede Tam Şansa Bağlı Deneme Planına göre kurulmuş ve yürütülmüştür. Elde edilen sonuçlar SPSS (2004) paket programında analize tabi tutulmuştur.

\section{ARAŞTIRMA BULGULARI VE TARTIŞMA}

\section{Dondurma Örneklerine Ait Fiziksel ve Kimyasal Analiz Sonuçları}

Dondurma örneklerinin fiziksel ve kimyasal özelliklerine ait sonuçlar Çizelge 3 'te verilmiştir. Elde edilen bulgulara göre, baharat uçucu yağı ilavesinin dondurma örneklerinin incelenen fiziksel ve kimyasal özellikleri üzerinde önemli bir etki meydana getirmediği $(\mathrm{P}>0,05)$, buna karşıllk depolama süresinin dondurma örneklerinin erime oranları üzerinde $\mathrm{P}<0,01$ düzeyinde etkili olduğu saptanmıştır. Dondurma örneklerine ait erime oranları depolama süresince düzenli bir şekilde artmıştı (Şekil 1). Güven ve ark., (2003) tarafindan yapılan bir araştırmada da benzer sonuçlar rapor edilmiştir. Bu durumun, buz kristallerinin yapısında meydana gelen değişimle ilgili olduğu tahmin edilmektedir (Olson ve ark., 2003).

Çizelge 3. Dondurma örneklerinin bazı fiziksel ve kimyasal özelliklerine ait ortalama değerler

\begin{tabular}{ccccccc}
\hline Örnek kodu & $\begin{array}{c}\text { Kurumadde } \\
(\boldsymbol{\%})\end{array}$ & $\begin{array}{c}\text { Yağ } \\
(\boldsymbol{\%})\end{array}$ & $\mathbf{p H}$ & $\begin{array}{c}\text { Asitlik } \\
(\boldsymbol{\%})\end{array}$ & $\begin{array}{c}\text { Protein } \\
(\boldsymbol{\%})\end{array}$ & $\begin{array}{c}\text { Hacim artışı } \\
(\boldsymbol{\%})\end{array}$ \\
\hline $\mathbf{E}$ & 39,21 & 14,45 & 6,47 & 0,26 & 3,61 & 29,38 \\
\hline $\mathbf{A 1}$ & 39,42 & 14,50 & 6,45 & 0,26 & 3,60 & 29,62 \\
\hline $\mathbf{A 2}$ & 39,81 & 14,10 & 6,41 & 0,25 & 3,62 & 29,39 \\
\hline B1 & 39,73 & 14,20 & 6,47 & 0,26 & 3,67 & 29,59 \\
\hline B2 & 39,81 & 14,35 & 6,45 & 0,25 & 3,65 & 29,04 \\
\hline C1 & 39,68 & 14,40 & 6,50 & 0,25 & 3,74 & 29,92 \\
\hline C2 & 39,91 & 14,30 & 6,50 & 0,26 & 3,64 & 29,61 \\
\hline D1 & 39,75 & 14,15 & 6,47 & 0,25 & 3,68 & 29,32 \\
\hline D2 & 39,68 & 14,35 & 6,46 & 0,26 & 3,64 & 29,43 \\
\hline $\boldsymbol{P}$ & 1,501 & 1,396 & 0,416 & 0,111 & 0,958 & 0,725 \\
\hline
\end{tabular}




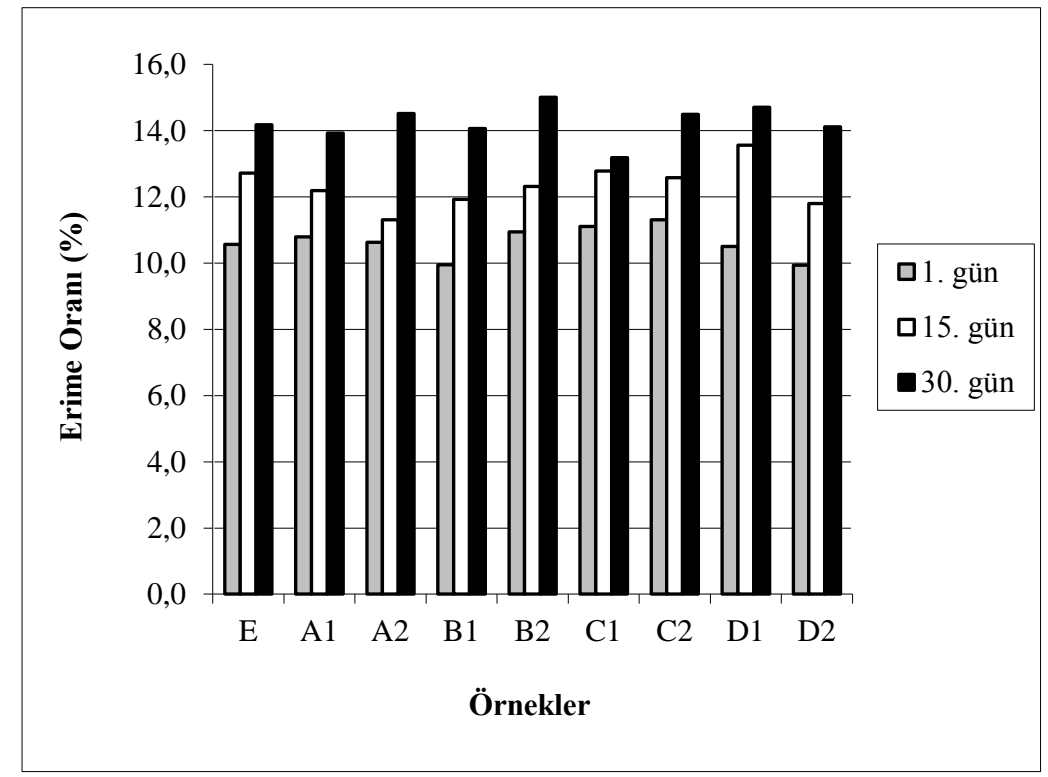

Şekil 1. Depolama periyodunca dondurma örneklerinin erime oranlarında meydana gelen değişim

\section{Dondurma Örneklerinin Duyusal Analiz Sonuçları}

Yapılan varyans analizi sonucunda, baharat uçucu yağı çeşidi, düzeyi ve depolama süresinin dondurma örneklerinin renk ve görünüş değerleri üzerinde istatistiksel olarak önemli bir etkide bulunmadığ $\breve{g}_{(}(\mathrm{P}>0,05)$ tespit edilmiştir. Dondurma örneklerine ait yapı ve kıvam değerleri baharat uçucu yağı çeşidi ve düzeyi bakımından benzer bir değişim göstermiş, buna karş1lık, depolama periyodunun etkisi istatistiksel açıdan önemli $(\mathrm{P}<0,01)$ çıkmıştır (Çizelge 4). Farklılığın hangi periyotlar arasında olduğunu belirlemek amacıyla yapılan Duncan çoklu karşılaştırma testi sonucunda ise, 1. gün ile 15. gün arasındaki farkın önemsiz, buna karşılık 30. günün diğer iki periyottan önemli düzeyde $(\mathrm{P}<0,01)$ farklı olduğu bulunmuştur. Dondurma örnekleri yapı ve kıvam bakımından en fazla 30. günde beğenilmiştir.

\%0.2 düzeyinde Hindistan cevizi uçucu yağı içeren örnek (B1), duyusal analizlerde tat ve koku bakımından en yüksek puanı $(4,57)$ almıştır. Dolayısıyla, panelistler tarafından bütün dondurma örnekleri içerisinde en fazla beğenilen örnek olmuştur. Buna karşılık, \%0.4 düzeyinde karanfil uçucu yağ1 içeren örnek (D2) en az beğenilen $(3,32)$ örnek olmuştur. Ayrıca, genel olarak \%0,2 düzeyinde baharat uçucu yağı içeren örnekler, \%0,4 düzeyine göre daha fazla beğenilmiştir. 
Çizelge 4. Dondurma örneklerine ait duyusal analiz sonuçları

\begin{tabular}{cccc}
\hline Dondurma Örnekleri & Renk ve Görünüş & Yapı ve Kıvam & Tat ve Koku \\
\hline E & 4,86 & 4,60 & $4,40^{\mathrm{a}}$ \\
\hline A1 & 4,81 & 4,43 & $3,97^{\mathrm{bc}}$ \\
\hline A2 & 4,83 & 4,51 & $3,72^{\mathrm{cd}}$ \\
\hline B1 & 4,92 & 4,50 & $4,57^{\mathrm{a}}$ \\
\hline B2 & 4,83 & 4,43 & $4,12^{\mathrm{ab}}$ \\
\hline C1 & 4,80 & 4,36 & $3,89^{\mathrm{bc}}$ \\
\hline C2 & 4,80 & 4,42 & $3,61^{\mathrm{cd}}$ \\
\hline D1 & 4,86 & 4,47 & $3,43^{\mathrm{d}}$ \\
\hline D2 & 4,81 & 4,48 & $3,32^{\mathrm{d}}$ \\
\hline $\boldsymbol{P}$ & 0,361 & 0,468 & $8,350^{* *}$ \\
\hline Depolama Periyodu (Gün) & & & \\
\hline $\mathbf{1 .}$ & 4,81 & $4,31^{\mathrm{b}}$ & 3,89 \\
\hline $\mathbf{1 5}$. & 4,81 & $4,37^{\mathrm{b}}$ & 3,85 \\
\hline $\mathbf{3 0 .}$ & 4,89 & $4,71^{\mathrm{a}}$ & 3,96 \\
\hline $\boldsymbol{P}$ & 1,571 & $14,149^{* *}$ & 0,427 \\
\hline
\end{tabular}

a, b, c, d Farklı harfle gösterilen ortalamalar arasındaki fark istatistiksel olarak önemlidir, ${ }^{* *} \boldsymbol{P}<0,01$

\section{Deneme Dondurmalara Ait Mikrobiyolojik Analiz Sonuçları}

Deneme dondurma örneklerine ait ortalama koliform bakteri ve psikrotrof bakteri sayıları ile maya ve küf sayıları tespit edilebilir sınırın altında bulunmuş̧ur ( $<10 \mathrm{kob} / \mathrm{g})$. TS 4265 No'lu Dondurma Standardı'na göre, dondurmalarda bulunabilecek en fazla koliform bakteri sayısının $100 \mathrm{kob} / \mathrm{g}$ düzeyinde olabileceği hükme bağlanmıştır (Anonim, 2013). Analiz edilen dondurma örneklerinin koliform bakteri sayıları bu değerin altında çıkmıştır. TS 4265 No'lu Dondurma Standardında, dondurmalarda bulunabilecek maya-küf sayılarıyla ilgili herhangi bir hüküm bulunmamaktadır.

Dondurulmuş ürünlerin raf ömrünü uzatmak için, ürün işleme esnasında psikrotrofik mikroorganizmaların tam olarak yıkımı çok önemlidir (Feijoo ve ark., 1997). Psikrotrof bakteriler 7 ${ }^{\circ} \mathrm{C}$ ve altında çoğalabilen mikroorganizmalar olarak tanımlanmaktadır. Psikrotroflar genellikle süt ve süt ürünlerinde bulunan protein, yağ, fosfolipitler, glikoproteinler ve glikolipitleri parçalayan ekstraselüler enzimleri fazla miktarlarda üreten ve bu ürünlerde kötü tat ve aroma, yapı ve tekstür ve renkte değişmeler meydana getiren bakterilerdir (Marshall, 1979; Rowe ve ark., 2003). Dondurma örneklerinde belirlenen psikrotrof bakteri sayıları deneme dondurmaların bakteriyolojik kalitesinin iyi olduğunu ve üretim sonrası herhangi bir bulaşmanın söz konusu olmadığını göstermektedir.

\section{SONUÇ VE ÖNERILLER}

Sonuç olarak, baharat uçucu yağı çeşidi ve düzeyinin dondurmanın fiziksel ve kimyasal özellikleri üzerinde önemli bir etki meydana getirmediği $(\mathrm{P}>0,05)$, buna karşllık depolama süresinin erime oranları üzerinde etkili olduğu $(\mathrm{P}<0,01)$ saptanmıştır. Duyusal değerlendirmelere göre $\% 0,2$ ve $\% 0,4$ düzeyinde ilave edilen baharat uçucu yağı, deneme dondurmaların dış görünüşü, yapı ve kıvamı üzerinde önemli bir değişiklik meydana getirmemiştir. Buna karşılık, \%0,2 düzeyinde Hindistan cevizi uçucu yağı içeren örnek, tat ve koku bakımından, panelistler tarafından en fazla, \%0,4 düzeyinde karanfil uçucu yağ 1 içeren örnek ise en az beğenilen örnek olmuştur. Analiz edilen dondurma örneklerinin mikrobiyolojik nitelikleri ise, TS 4265 Dondurma Standardı'na uygun bulunmuştur. Kısaca; uygun çeşit ve düzeyde baharat uçucu yağı seçilerek dondurma üretiminde kullanılması halinde, sade dondurmaya göre ürünün fiziksel ve kimyasal niteliklerinde herhangi bir değişiklik meydana getirmeden, tüketiciler tarafından daha fazla beğenilen ve fonksiyonel özelliklere sahip dondurma üretiminin gerçekleştirilebileceği ortaya konulmuştur.

\section{KAYNAKLAR}

Akın, N., 2009. Dondurma Bilimi ve Teknolojisi. Damla Ofset, 425 s., Konya. Anonim, 1992. Dondurma Standardı. Türk Standartları Enstitüsü, TS-4265, Ankara.

Anonim, 2013. Dondurma Standardı. Türk Standartları Enstitüsü, TS-4265, Ankara.

Burt, S., 2004. Essential oils: Their antibacterial properties and potential applications in foods-a review. Int J Food Microbiol, 94, 223 - 253. 
Calo, J.R., Crandall, P.G., O’Bryan, C.A., and Ricke, S.C., 2015. Essential oils as antimicrobials in food systems - A review. Food Control, 54, 111-119.

Cruz, A.G., Antunes, A.E.C., Sousa, A.L.O.P., Faria, J.A.F., and Saad, S.M.I., 2009. Ice-cream as a probiotic food carrier. Food Res Int, 42, 1233-1239.

Feijoo, S. C., Hayes, W. W., Watson, C. E., and Martin, J. H., 1997. Effect of microfluidizer technology on Bacillus licheniformis spores in ice cream mix. J Dairy Sci, 80 (9), 2184-2187.

Feng, W., and Zheng, X., 2007. Essential oils to control Alternaria alternata in vitro and in vivo. Food Control, $18,1126-1130$.

Güven, M., Karaca O. B., and Kacar, A., 2003. The effects of the combined use of stabilizers containing locust bean gum and of the storage time on Kahramanmaraş-type ice creams. Int J Dairy Technol, 56(4), 223 228.

Kurt, A., Çakmakçı, S. ve Çağlar A., 2014. Süt ve mamulleri muayene ve analiz metotları rehberi. Atatürk Üniv. Ziraat Fak. Yay. No. 18, 238 s., Erzurum.

Manikandan, A., Shipra, S., Sri Nidhi, N., and Sivakumar, A., 2015. Antioxidant and antibacterial studies on essential oils used as alternatives for chemical preservatives. J. Nat. Prod. Plant Resour., 5 (6):9-14.

Marshall, R. T., 1979. Psychrotrophic bacteria - their relationship to raw milk quality and keeping quality of cottage cheese. Marshall \& Italian Specialty Cheese Seminars. Food Science and Nutrition, University of Missouri, Columbia, Missouri 65211, USA.

Negi, P.S., 2012. Plant extracts for the control of bacterial growth: Efficacy, stability and safety issues for food application. Int J Food Microbiol, 156, 7-17.

Olson, D. W., White C. H., and Watson C. E., 2003. Properties of frozen dairy desserts processed by microfluidization of their mixes. J Dairy Sci, 86, 1157-1162.

Prakash, B., Kedia, A., Mishra, P.K., and Dubey, N.K., 2015. Plant essential oils as food preservatives to control moulds, mycotoxin contamination and oxidative deterioration of agri-food commodities - Potentials and challenges. Food Control, 47, 381-391.

Rowe, M. T., Dunstall, G., Kilpatrick, D., and Wisdom, A.B., 2003. Effect of growth phase on the subsequent growth kinetics of psychrotrophic bacteria of raw milk origin. Int J Dairy Technol, 56(1), 35-38.

SPSS Inc. Statistical package for the social sciences SPSS ver., 2004. 13.0 for Windows.Chicago, IL.

Tekinşen, O. C., 2000. Süt ürünleri teknolojisi (3.baskı). Selçuk Üniversitesi Basımevi, 329 s., Konya.

Viuda-Martos, M., Ruiz-Navajas, Y., Fernández-López, J., and Pérez-Álvarez, J., 2008. Antifungal activity of lemon (Citrus lemon L.), mandarin (Citrus reticulata L.), grapefruit (Citrus paradisi L.) and orange (Citrus sinensis L.) essential oils. Food Control, 19, 1130-1138. 